\title{
BONE MINERAL DENSITY IN ANKYLOSING SPONDYLITIS
}

\author{
DEXA COMPARISON OF CONTROL SUBJECTS WITH MILD AND \\ ADVANCED CASES
}

A. B. MUllajI, S. S. UPADHYAY, E. K. W. HO

From the Duchess of Kent Children's Hospital, Hong Kong

We have used dual-energy $\mathrm{X}$-ray absorptiometry to measure bone mineral density (BMD) in patients with ankylosing spondylitis comparing $\mathbf{4 1}$ healthy control subjects and 33 patients with either mild or advanced ankylosing spondylitis. A Norland XR-28 bone densitometer was used to measure the BMD of the lumbar spine and that of the head, trunk, arms, femoral neck, Ward's triangle, legs, pelvis, and total body.

Mild ankylosing spondylitis was defined as that showing no or incipient syndesmophytes between L1 and L5 vertebrae: we studied 16 men of mean age 37 years and six women of mean age 37 years. Advanced ankylosing spondylitis, in 11 men of mean age 42 years, showed a bamboo spine with bridging syndesmophytes across all disc spaces between L1 and L5.

The mean BMD of the lumbar spine was significantly different in the patients and control subjects of the same sex $(0.01<p<0.05$, analysis of variance), being significantly reduced compared with control subjects in mild disease $(0.001<p<0.01, t$-test $)$ and significantly increased in advanced disease over control subjects $(0.01<p<0.05 ; t$-test $)$ and over patients with mild disease $(0.001<\mathrm{p}<0.01 ; t$-test). The relevance of these findings to the aetiology and pathogenesis of spinal deformities and other complications in ankylosing spondylitis is discussed.

J Bone Joint Surg [Br] 1994; 76-B:660-5.

Received 25 October 1993; Accepted 22 December 1993

A. B. Mullaji, MS Orth, MCh Orth, Consultant Orthopaedic Surgeon

S. S. Upadhyay, D Orth, MS Orth, DM, Senior Medical Officer

E. K. W. Ho, FRCS G, FRACS, Former Medical Director

Duchess of Kent Children's Hospital, 12 Sandy Bay Road, Hong Kong.

Correspondence should be sent to Dr A. B. Mullaji at 4 Indus Court, 'A' Road, Churchgate, Bombay 400 020, India.

C1994 British Editorial Society of Bone and Joint Surgery

0301-620X/94/4807\$2.00

Ankylosing spondylitis is of unknown aetiology, affecting mainly the sacroiliac joint and the spine. At first there is synovitis and enthesopathy, but endochondral ossification later causes bony ankylosis (Percy and Lentle 1980). There are many radiological and pathological descriptions of articular change and new bone formation (Spencer et al 1979; Ball 1980; Resnick and Niwayama 1988), but few explanations have been offered for the cause of the kyphotic deformity which is a hallmark of the disease. Buckley (1932) first proposed that "rarefaction or osteoporosis of the vertebral bodies is responsible for the curvatures which are apt to develop". Few subsequent papers have discussed osteoporosis; some consider it to be a late manifestation (Hanson, Shagrin and Duncan 1971) and others suggest that it is an early change (Will et al 1989; Devogelaer et al 1992).

Until recently, osteoporosis in ankylosing spondylitis was assessed from radiographs (Hanson et al 1971; Spencer et al 1979), which are known to be inaccurate. Will et al (1989) and Devogelaer et al (1992) measured bone mass in ankylosing spondylitis by non-invasive techniques such as single-photon absorptiometry, dualphoton absorptiometry, and quantitative CT. Dual-energy $\mathrm{X}$-ray absorptiometry (DEXA) is a new technique with significant advantages in terms of improved precision, accuracy, shorter scanning times and reduced radiation dose (Pun and Wong 1991).

We know of no other report of the use of DEXA to evaluate bone mineral density (BMD) in ankylosing spondylitis. We aimed to determine whether the BMD differed from control values in different regions of the body, especially in the lumbar spine, in patients with mild and advanced ankylosing spondylitis and whether it was different in mild and advanced disease.

\section{PATIENTS AND METHODS}

We performed bone densitometry in 41 healthy control subjects and 33 patients with ankylosing spondylitis. The control group included 28 men and 13 premenopausal women; they had average ages of 32.3 years ( 23 to 50 ) and 37.8 years (27 to 47 ) respectively.

Patients with ankylosing spondylitis were selected from regular attenders at our ankylosing spondylitis clinic. All satisfied the New York criteria (Bennett and Burch 

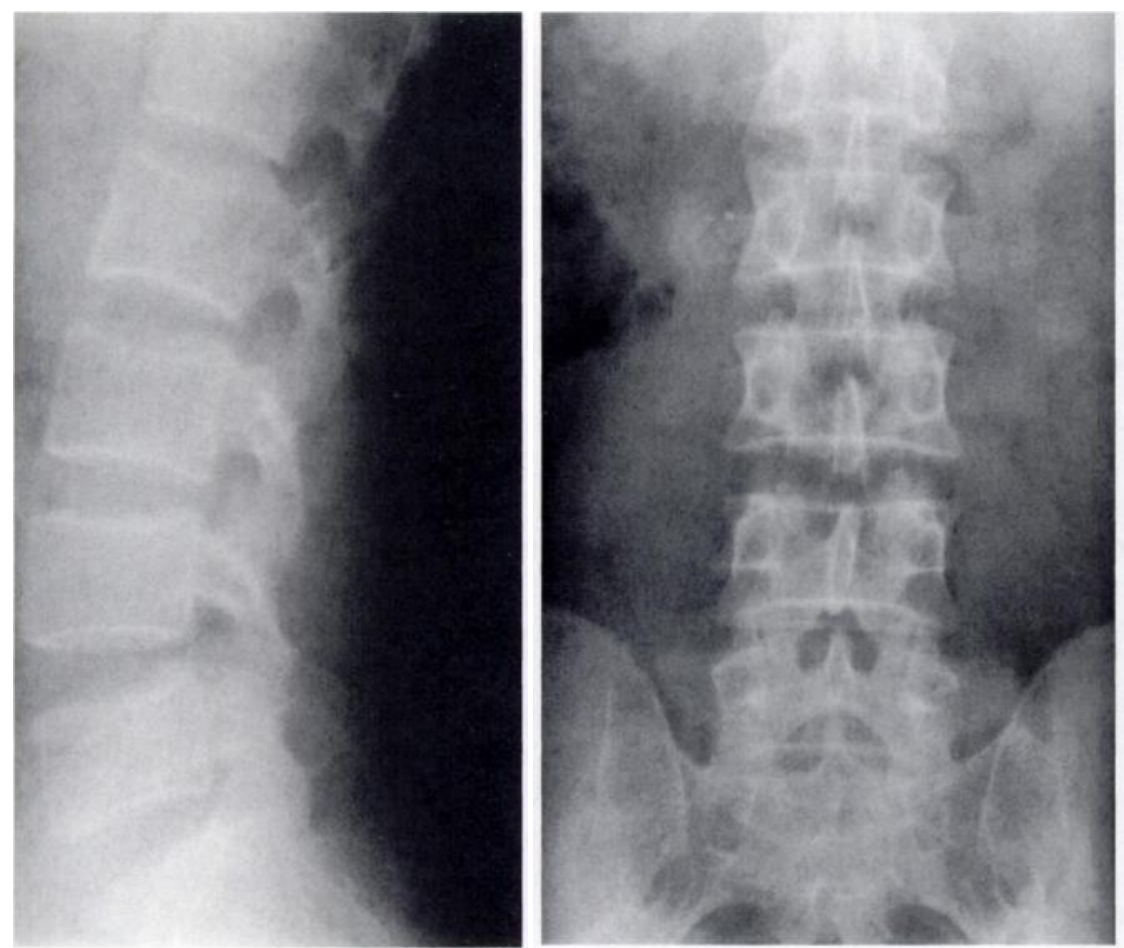

Fig. 1

Radiographs showing the appearance of mild ankylosing spondylitis, with squaring of the vertebral bodies and the absence of syndesmophytes.
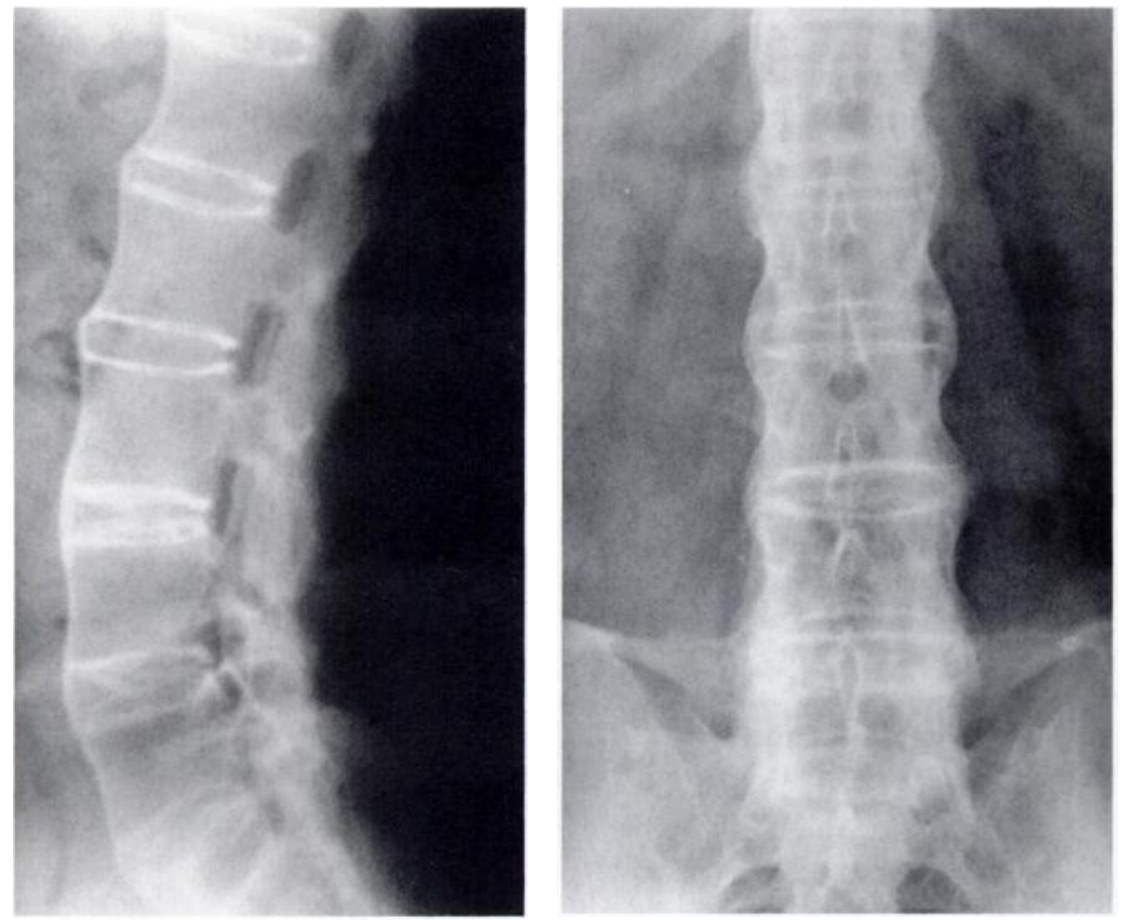

Fig. 2

Radiographs showing the appearance of advanced ankylosing spondylitis with a typical bamboo spine.

1967) and all were positive for HLA B27. We excluded men over 60 and women over 50 years and patients with corrective osteotomies, known compression fractures, or pseudarthroses between L1 and L5. All patients were taking NSAIDs and followed a regular exercise regime. None had received radiotherapy or corticosteroids.

We divided the patients with ankylosing spondylitis into two distinct groups on the basis of radiographic findings. The first group, with mild involvement of the lumbar spine, had radiographs which showed no or only incipient syndesmophytes in the lumbar spine between L1 and L5 (Fig. 1). In the second group, classified as advanced ankylosing spondylitis, the patients showed bridging syndesmophytes across all the disc spaces between L1 and L5 vertebrae (bamboo spine; Fig. 2).

There were 16 men of mean age $36.6 \pm 7.5$ years $(25$ to 60 ) with mild disease of mean duration 8.7 years (SD $4.1 ; 2$ to 17$)$ and 11 of mean age $42.5 \pm 10.1$ years ( 29 to 
60) with advanced changes of mean duration 11.7 years (SD $4.4 ; 5$ to 18). Six women of mean age $36.7 \pm 8.6$ years (24 to 50) all had mild disease for a mean duration of 6.8 years (SD $3.8 ; 3$ to 12 ).

We used a Norland XR-28 bone densitometer (Norland Corp, Fort Atkinson, Wisconsin) to measure the BMD. The radiation source operated at $100 \mathrm{kV}$ constant potential and $1.0 \mathrm{~mA}$ current. Dual-energy beams, attenuated after passing through the subject, were detected by a crystal detector and the bone mineral content was obtained by subtracting the attenuation of soft tissue from that of adjacent bone and soft tissue. This was expressed relative to the projected area of bone to give an areaspecific BMD in $\mathrm{g} / \mathrm{cm}^{2}$. The precision and accuracy were checked against an anatomical spine phantom (Norland Corp) and long-term reproducibility was monitored by daily scanning of phantoms. We measured the BMD of the head, arms, trunk, lumbar spine (L2 to L4), pelvis, femoral neck, Ward's triangle in the upper femur, legs, and the total body.

Recent radiographs of the pelvis and spine were examined to assess the severity of involvement of the sacroiliac joints and the lumbar spine. The former were graded as normal, or as showing erosions, sclerosis, erosions and sclerosis, or complete ankylosis. The lumbar vertebrae were classified as unaffected, or showing squaring, erosion, incipient syndesmophytes, or complete syndesmophytes (bamboo spine).

Statistical analysis was performed using an IBM/PC computer and SPSS/PC+ version 3.0 statistical software package. We used Student's $t$-test and analysis of variance, considering $\mathrm{p}$ values of 0.05 or less as statistically significant.

\section{RESULTS}

There was no significant difference in age between the control subjects and patients with mild ankylosing spondylitis, but those with advanced ankylosing spondylitis were older than the control group $(p<0.05)$. There was no significant difference in the duration of disease between patients with mild and advanced ankylosing spondylitis by the $t$-test.

In the 22 patients with mild disease there was a normal vertebral appearance in nine, squaring in ten, and incipient syndesmophytes in three. The sacroiliac joint was ankylosed bilaterally in seven, and showed erosions and sclerosis in the remaining 15 . All the 11 patients with advanced disease had a kyphotic bamboo spine and complete ankylosis of the sacroiliac joint. Six patients had involvement of one or both hips.

We analysed data separately for men and women because the mean BMD values were different in control male and female subjects. The mean values of BMD and comparison of these means using Student's $t$-test are shown in Table I for men and in Table II for women.

Mild disease. In men with mild ankylosing spondylitis compared with the control group, the mean BMD was significantly reduced in the lumbar spine, Ward's triangle, the femoral neck, and the legs $(0.001<p<0.01$; Table I). In women, the mean BMD of the lumbar spine and Ward's triangle was similarly reduced $(0.001<\mathrm{p}<0.01$ and $0.01<\mathrm{p}<0.05$ respectively; Table II).

Advanced disease. In patients with advanced ankylosing spondylitis, the mean BMD of the lumbar spine was significantly higher than that of the control group $(0.01<\mathrm{p}<0.05, t$-test $)$. The mean BMD of the lumbar spine, trunk and total body was also significantly greater than that for patients with mild ankylosing spondylitis $(0.001<\mathrm{p}<0.01, t$-test $)$.

Analysis of variance (ANOVA) showed that values of BMD for the lumbar spine and Ward's triangle were significantly different on comparing control subjects, mild AS patients, and advanced AS patients separately for men and women $(p<0.05)$. When we eliminated the possible effect of age on these values (by performing ANOVA with age as covariate), only the values for lumbar spine BMD were significantly different between the groups in both male and female cohorts $(0.01<p<0.05)$.

\section{DISCUSSION}

About $50 \%$ of spinal bone mass has to be lost before demineralisation becomes apparent on standard radiographs (Pun and Wong 1991). Radiography is therefore relatively insensitive in assessing skeletal changes (Percy and Lentle 1980). DEXA is the most recent technique and provides a nearly tenfold improvement in precision over dual-photon absorptiometry for measurement of spinal bone mineral (Mazess 1990; Pun and Wong 1991).

Both men and women with mild disease showed a significant reduction of BMD in the lumbar spine despite the absence or paucity of radiological changes. This has been reported for men only using dual-photon absorptiometry by Will et al (1989) but Devogelaer et al (1992), however, did not find a similar change in women. By contrast we found that patients with advanced disease had a significantly increased mean lumbar BMD compared with both the control group and patients with mild disease. Dual-photon absorptiometry failed to detect any difference between patients with severe disease and the control group (Devogelaer et al 1992), but the difference may possibly be due to the less sensitivity and accuracy of dual-photon absorptiometry.

In this study we found that the BMD of the appendicular skeleton, although changed, showed only non-significant alterations in patients with ankylosing spondylitis, as reported for dual-photon absorptiometry by Devogelaer et al (1992).

Our finding of changes only in the axial skeleton raises the question of cause. In mild ankylosing spondylitis, osteoporosis may result from the disease itself, possibly due to inflammatory and cytokine-induced changes. Immobility is unlikely to be a factor as our 
Table I. Mean values \pm SD for BMD in $\mathrm{g} / \mathrm{cm}^{2}$ and their comparison between male control subjects and men with mild and advanced ankylosing spondylitis

\begin{tabular}{|c|c|c|c|c|c|c|}
\hline & \multirow{2}{*}{$\begin{array}{l}\text { Normal } \\
\text { control } \\
\text { men } \\
(n=28)\end{array}$} & \multicolumn{2}{|c|}{ Ankylosing spondylitis } & \multicolumn{3}{|c|}{ p values by Student's $t$-test } \\
\hline & & $\begin{array}{l}\text { Mild } \\
(n=16)\end{array}$ & $\begin{array}{l}\text { Advanced } \\
(n=11)\end{array}$ & $\begin{array}{l}\text { Control v } \\
\text { mild }\end{array}$ & $\begin{array}{l}\text { Control v } \\
\text { advanced }\end{array}$ & $\begin{array}{l}\text { Mild } \mathbf{v} \\
\text { advanced }\end{array}$ \\
\hline Head & $1.48 \pm 0.16$ & $1.48 \pm 0.19$ & $1.51 \pm 0.16$ & NS* & NS & NS \\
\hline Arm & $0.76 \pm 0.08$ & $0.77 \pm 0.08$ & $0.80 \pm 0.04$ & NS & NS & NS \\
\hline Trunk & $0.41 \pm 0.09$ & $0.39 \pm 0.05$ & $0.45 \pm 0.09$ & NS & NS & $0.001<\mathrm{p}<0.01$ \\
\hline Lumbar spine (L2 to L4) & $0.98 \pm 0.13$ & $0.89 \pm 0.12$ & $1.08 \pm 0.17$ & $0.001<\mathrm{p}<0.01$ & $0.01<\mathrm{p}<0.05$ & $0.001<\mathrm{p}<0.01$ \\
\hline Pelvis & $0.81 \pm 0.12$ & $0.75 \pm 0.11$ & $0.82 \pm 0.09$ & NS & NS & NS \\
\hline Femoral neck & $0.87 \pm 0.15$ & $0.76 \pm 0.15$ & $0.79 \pm 0.12$ & $0.001<p<0.01$ & NS & NS \\
\hline Ward's triangle & $0.82 \pm 0.21$ & $0.64 \pm 0.16$ & $0.69 \pm 0.11$ & $0.001<p<0.01$ & NS & NS \\
\hline Legs & $0.92 \pm 0.09$ & $0.83 \pm 0.11$ & $0.91 \pm 0.08$ & $0.001<p<0.01$ & NS & NS \\
\hline Total body & $0.76 \pm 0.08$ & $0.72 \pm 0.07$ & $0.80 \pm 0.06$ & NS & NS & $0.001<p<0.01$ \\
\hline
\end{tabular}

* not significant

Table II. Mean values $\pm \mathrm{SD}$ for $\mathrm{BMD}$ in $\mathrm{g} / \mathrm{cm}^{2}$ and their comparison between female control subjects and women with mild ankylosing spondylitis

\begin{tabular}{llll}
\hline & $\begin{array}{l}\text { Normal } \\
\text { control } \\
\text { women } \\
(\mathbf{n}=13)\end{array}$ & $\begin{array}{l}\text { Mild } \\
\text { ankylosing } \\
\text { spondylitis } \\
\text { (n=6) }\end{array}$ & $\begin{array}{l}\text { p values by Student's } \text { t-test } \\
\text { of control v mild }\end{array}$ \\
\hline Head & $1.77 \pm 0.24$ & $1.61 \pm 0.25$ & NS* $^{*}$ \\
Arm & $0.77 \pm 0.08$ & $0.76 \pm 0.06$ & NS \\
Trunk & $0.49 \pm 0.07$ & $0.46 \pm 0.01$ & NS \\
Lumbar spine (L2 to L4) & $1.09 \pm 0.15$ & $0.9 \pm 0.1$ & $0.001<\mathrm{p}<0.01$ \\
Pelvis & $0.86 \pm 0.09$ & $0.8 \pm 0.07$ & NS \\
Femoral neck & $0.83 \pm 0.12$ & $0.76 \pm 0.05$ & NS \\
Ward's triangle & $0.82 \pm 0.15$ & $0.68 \pm 0.08$ & $0.01<\mathrm{p}<0.05$ \\
Legs & $0.88 \pm 0.07$ & $0.83 \pm 0.5$ & NS \\
Total body & $0.82 \pm 0.07$ & $0.77 \pm 0.04$ & NS \\
\hline
\end{tabular}

* not significant

patients were on regular exercise therapy. NSAIDs have not been shown to cause osteoporosis and their influence may be discounted. Devogelaer et al (1992) postulated a hormonal cause to explain their finding of male predisposition to BMD alterations, but in this cohort we had identical findings in male and female patients. More work is required to determine the cause of osteoporosis in early ankylosing spondylitis.

The increased lumbar BMD which we found in patients with advanced ankylosing spondylitis conflicts with the general appearance of lateral radiographs which show apparent osteopenia and loss of trabecular bone. In a radiographic study, Hanson et al (1971) found that 29 of 50 patients with ankylosing spondylitis had moderate to severe osteoporosis which was related to the duration and severity of disease judged by the need for drug therapy. Our patients with advanced ankylosing spondy- litis had a significantly increased BMD of the lumbar spine both in comparison with the control group and with patients suffering mild disease. The reason for these seemingly contrary findings may be that osteoporosis persists into the advanced stage as trabecular osteopenia, but that advanced enthesopathy is followed by new bone formation in the peripheral layers of the vertebral column which results in an increased BMD of the lumbar spine. This theory is supported by the finding of decreased trabecular density on quantitative CT in three patients with bamboo spines by Devogelaer et al (1992).

We suggest that axial osteoporosis, shown by the reduced lumbar spine $\mathrm{BMD}$, may predispose to the development of a kyphotic deformity with the passage of time (Fig. 3a). The subsequent appearance of bridging syndesmophytes and ligamentous ossification may later increase the overall density of the axial skeleton. The 

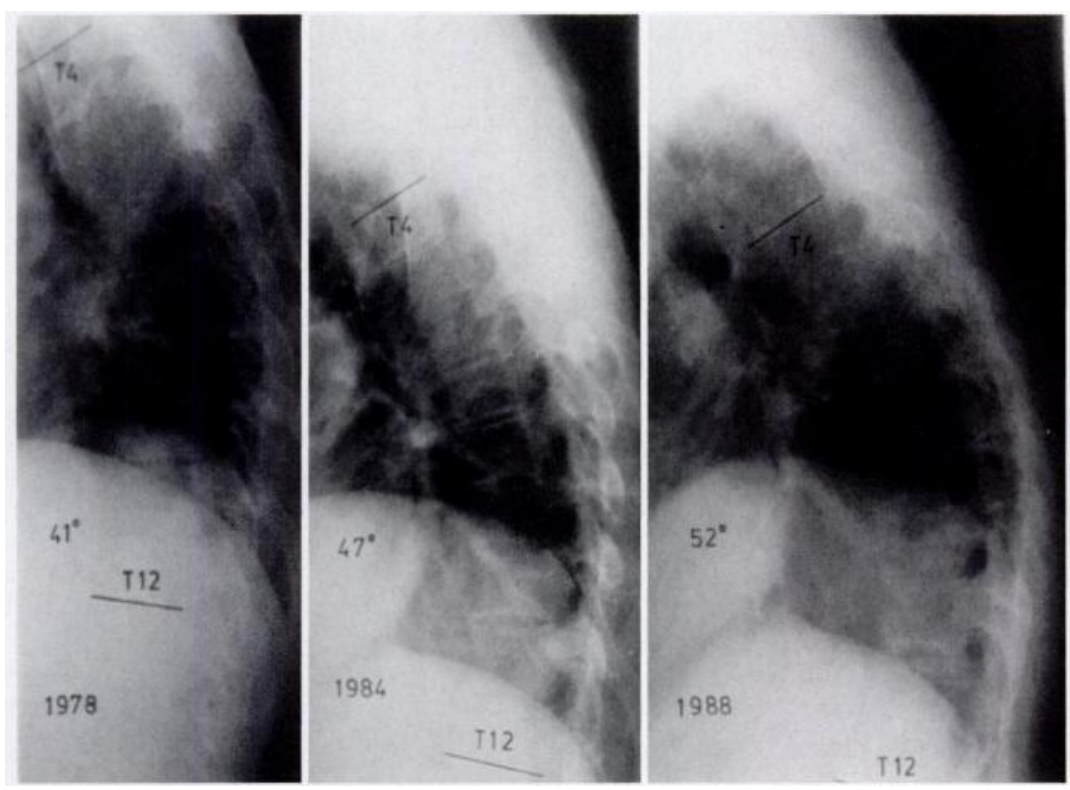

Fig. 3a
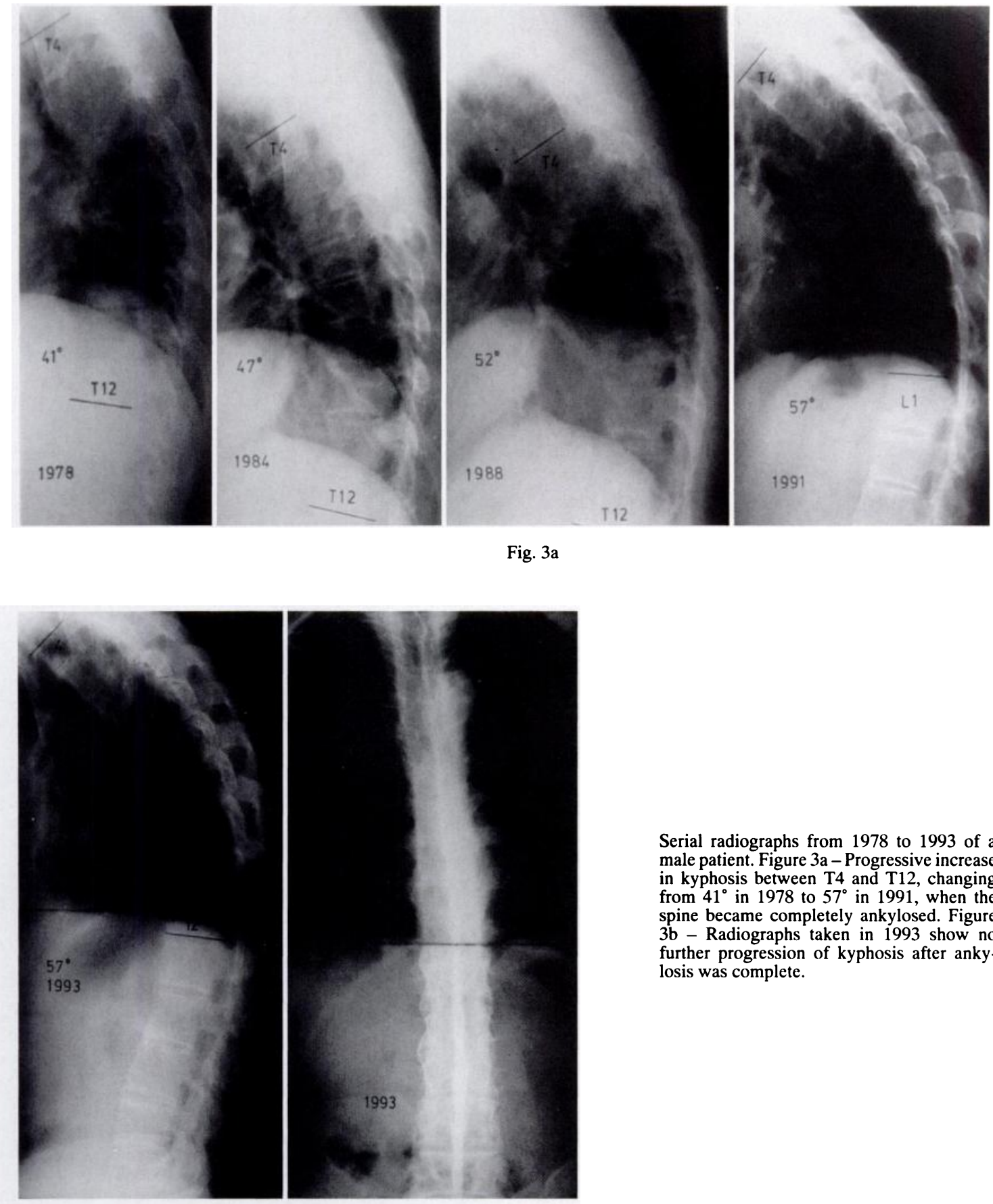

Serial radiographs from 1978 to 1993 of a male patient. Figure $3 a$ - Progressive increase in kyphosis between T4 and T12, changing from $41^{\circ}$ in 1978 to $57^{\circ}$ in 1991 , when the spine became completely ankylosed. Figure 3 b - Radiographs taken in 1993 show no further progression of kyphosis after ankylosis was complete.

Fig. 3b

influence of this increased BMD in preventing further deformation of the bamboo spine (Fig. 3b) will require a longitudinal study of patients with ankylosing spondylitis.

Axial osteoporosis during the mild stage of the disease may also contribute to the development of compression fractures, leading to further kyphosis. Ralston et al (1990) studied 111 patients with ankylosing spondylitis and found that 14 of 15 patients with compression fractures had radiographic osteoporosis but no syndesmophytes. None of our patients had compression fractures but our finding of a decreased lumbar BMD in mild ankylosing spondylitis supports this observation.
Patients with advanced ankylosing spondylitis and increased spinal BMD have new bone formation in the peripheral layers of the spinal column, and the segmental form changes into a curved tubular structure with tension and compression surfaces. This may explain the increased likelihood of transvertebral and transdiscal stress fractures (Thorngren, Liedberg and Aspelin 1981), rather than compression fractures, once the spine is completely ankylosed.

We have shown significant differences in BMD between patients with mild ankylosing spondylitis and those with severe disease despite the lack of significant 
difference in duration of symptoms. This may have a potential value in differentiating patients who will continue with mild disease for several years from those who will develop more severe disease. The relation between BMD and severity of disease in the axial skeleton may help to elucidate the aetiology and pathogenesis of the spinal deformities and complications of this disabling condition.

The authors acknowledge the help of Professor J. C. Y. Leong, Head of the Orthopaedic Department of the University of Hong Kong, and Dr K. D. K. Luk, the Medical Director of the Duchess of Kent Children's Hospital, Hong Kong.

No benefits in any form have been received or will be received from a commercial party related directly or indirectly to the subject of this article.

\section{REFERENCES}

Ball J. Pathology and pathogenesis. In: Moll JMH, ed. Ankylosing spondylitis. Edinburgh: Churchill Livingstone, 1980:96-112.

Bennett PH, Burch TA. New York symposium on population studies in the rheumatic diseases: new diagnostic criteria. Bull Rheum Dis 1967; $17: 453-8$

Buckley CW. Spondylitis deformans: its differential diagnosis and treatment by physical methods. Proc Roy Soc Med 1932; 26:105-10.
Devogelaer JP, Maldague B, Malghem J, Nagant de Deuxchaisnes C. Appendicular and vertebral bone mass in ankylosing spondylitis: a comparison of plain radiographs with single- and dual-photon absorptiometry and with quantitative computed tomography. Arthritis Rheum 1992; 35:1062-7.

Hanson CA, Shagrin JW, Duncan H. Vertebral osteoporosis in ankylosing spondylitis. Clin Orthop 1971; 74:59-64.

Mazess RB. Bone densitometry of the axial skeleton. Orthop Clin North Am 1990; 21:51-63.

Percy JS, Lentle B. Radiological and scintigraphic features. In: Moll JMH, ed. Ankylosing spondylitis. Edinburgh: Churchill Livingstone, 1980 76-86.

Pun KK, Wong FHW. Importance of bone densitometry in clinical practice. J Western Pacific Orthop Ass 1991; 28:23-31.

Ralston SH, Urquhart GDK, Brzeski M, Sturrock RD. Prevalence of vertebral compression fractures due to osteoporosis in ankylosing spondylitis. Br Med J 1990; 300:563-5.

Resnick D, Niwayama G. Ankylosing spondylitis. In: Resnick D, Niwayama G, eds. Diagnosis of bone and joint disorders. Philadelphia, etc: W.B. Saunders Co, 1988:1103-70.

Spencer DG, Park WM, Dick HM, Papazogiou SN, Buchanan WW. Radiological manifestations in 200 patients with ankylosing spondylitis: correlation with clinical features and HLA-B27.J Rheumatol 1979; 6:305-15.

Thorngren KG, Liedberg E, Aspelin P. Fractures of the thoracic and lumbar spine in ankylosing spondylitis. Arch Orthop Trauma Surg 1981; 98:101-7.

Will R, Bhalla AK, Palmer R, Ring R, Calin A. Osteoporosis in early ankylosing spondylitis: a primary pathological event? Lancet 1989 ; II:1483-5. 